\title{
Diversity of Bacterial Photosymbionts in Lubomirskiidae Sponges from Lake Baikal
}

\author{
Nina V. Kulakova, Natalia N. Denikina, and Sergei I. Belikov \\ Limnological Institute, Siberian Branch of the Russian Academy of Sciences, Ulan-Batorskaya Street 3, Irkutsk 664033, Russia \\ Correspondence should be addressed to Nina V. Kulakova; kulakova@lin.irk.ru
}

Received 26 May 2014; Revised 28 October 2014; Accepted 10 November 2014; Published 20 November 2014

Academic Editor: Alexandre Rosado

Copyright ( 2014 Nina V. Kulakova et al. This is an open access article distributed under the Creative Commons Attribution License, which permits unrestricted use, distribution, and reproduction in any medium, provided the original work is properly cited.

\begin{abstract}
Sponges are permanent benthos residents which establish complex associations with a variety of microorganisms that raise interest in the nature of sponge-symbionts interactions. A molecular approach, based on the identification of the 16S rRNA and ribulose-1,5-bisphosphate carboxylase/oxygenase large subunit genes, was applied to investigate diversity and phylogeny of bacterial phototrophs associated with four species of Lubomirskiidae in Lake Baikal. The phylogeny inferred from both genes showed three main clusters of Synechococcus associated with Baikalian sponges. One of the clusters belonged to the cosmopolitan Synechococcus rubescens group and the two other were not related to any of the assigned phylogenetic groups but placed as sister clusters to $S$. rubescens. These results expanded the understanding of freshwater sponge-associated photoautotroph diversity and suggested that the three phylogenetic groups of Synechococcus are common photosynthetic symbionts in Lubomirskiidae sponges.
\end{abstract}

\section{Introduction}

Sponges are an important component of the marine and freshwater benthos ecosystems that establish associations with a great diversity of unicellular and multicellular organisms [1]. At the photosynthetic zone, sponges can benefit from phototrophic symbionts which fix carbon using the CalvinBenson cycle and provide products of photosynthesis to the host [2-4].

Photosynthetic symbionts are prevalent in marine sponges of coastal regions worldwide where they contribute significantly to net primary production $[5,6]$. From onethird to more than half of the sponges of tropical and temperate regions harbor a high level of photosynthetic symbionts $[7,8]$. In Lake Baikal, sponges are necessary components of the benthos and ubiquitous on rocky grounds in the littoral zone. Sponges from the endemic family Lubomirskiidae are widely distributed in Lake Baikal and often harbor photosynthetic symbionts. From 14 described species of Lubomirskiidae [9], there are three common species among which photosynthetic Lubomirskia baicalensis (L. baicalensis) and Baikalospongia bacillifera (B. bacillifera) are widely distributed in the photic zone of Lake Baikal. In contrast to marine sponges, there is not a lot of data on photosynthetic symbionts of freshwater sponges, although associations with unicellular green algae, including Chlorella spp., Choricystis minor, yellow-green algae, and Chloroflexi have been shown in cosmopolitan sponges [4, 10-13] and cyanobacterial sequences detected in L. baicalensis [14]. Nevertheless, the identification and diversity of sponge-associated phototrophs in Lake Baikal are undetermined to date.

We analysed 16S rRNA and ribulose-1,5-bisphosphate carboxylase/oxygenase large subunit $(r b c \mathrm{~L})$ genes to identify and assess the diversity of photosynthetic symbionts in Baikalian sponges. Both molecular markers are widely used for analysis of genetic diversity [15-21].

\section{Materials and Methods}

Four species of sponges from the family Lubomirskiidae: L. baicalensis, Lubomirskia abietina (L. abietina), B. bacillifera, and Baikalospongia martinsoni (B. martinsoni) and water samples were collected from the Southern Basin 
of Lake Baikal at depths of $10-20 \mathrm{~m}$ by scuba diving (Table S1, see Supplementary Material available online at http://dx.doi.org/10.1155/2014/152097). Sponge tissue samples $\left(3-5 \mathrm{~cm}^{3}\right)$ were rinsed twice in $96 \%$ ethanol and stored at $4^{\circ} \mathrm{C}$ until DNA extraction. Species identification was based on external morphological characteristics and morphology of spicules according to the guides of Rezvoi (1936) and Efremova (2001) [22, 23].

Chlorophyll concentration was measured after 96\% ethanol extraction as described by Bergmann and Peters [24] and Webb et al. [25] from fresh frozen $\left(-20^{\circ} \mathrm{C}\right.$ ) samples (two replicates). Spectral absorbance scans were performed from 300-800 nm using a UV-visible spectrophotometer (Cintra10E, GBC, Australia).

Total DNA was extracted using the RiboSorb kit (AmpliSens, Russia) according to the manufacturer's protocol. The $R b c \mathrm{~L}$ gene was amplified in $15 \mu \mathrm{L}$ of PCR reaction mix (Screen Mix, Evrogen, Russia) with 10 pmol of each primer, cbbL 595f (5'-GACTTCACCAAAGACGACGA$\left.3^{\prime}\right)$ and $1387 \mathrm{r}\left(5^{\prime}\right.$-TCGAACTTGATTTCTTTCCA- $\left.3^{\prime}\right)$, as described by Elsaied and Naganuma [16]. Touchdown PCR was done in four repeats and mixed for each tissue sample. The amplification profile consisted of an initial denaturation at $95^{\circ} \mathrm{C}$ for $3 \mathrm{~min}$ followed by 5 touchdown cycles of $94^{\circ} \mathrm{C}$ for $20 \mathrm{~s}, 55^{\circ} \mathrm{C}$ for $20 \mathrm{~s}$, and $72^{\circ} \mathrm{C}$ for $1 \mathrm{~min}$ and then 20 cycles of $94^{\circ} \mathrm{C}$ for $20 \mathrm{~s}, 52^{\circ} \mathrm{C}$ for $20 \mathrm{~s}$, and $72^{\circ} \mathrm{C}$ for $1 \mathrm{~min}$ and 10 cycles of $94^{\circ} \mathrm{C}$ for $20 \mathrm{~s}, 50^{\circ} \mathrm{C}$ for $20 \mathrm{~s}$, and $72^{\circ} \mathrm{C}$ for $1 \mathrm{~min} .35 \mathrm{PCR}$ cycles were followed by a final extension at $72^{\circ} \mathrm{C}$ for $15 \mathrm{~min}$. The 16S rRNA gene was amplified with primers CYA106Fc (5' CGGACGGGTGAGTAACGCGTGA $3^{\prime}$ ) and CYA781R (5' GACTACWGGGGTATCTAATCCCWTT $3^{\prime}$ ) [26]. The amplification profile consisted of an initial denaturation at $95^{\circ} \mathrm{C}$ for $3 \mathrm{~min}$ followed by 30 cycles of $94^{\circ} \mathrm{C}$ for $20 \mathrm{~s}, 60^{\circ} \mathrm{C}$ for $20 \mathrm{~s}, 72^{\circ} \mathrm{C}$ for $1 \mathrm{~min}$ and a final extension at $72^{\circ} \mathrm{C}$ for $15 \mathrm{~min}$.

The PCR products were detected by electrophoresis in $0.8 \%$ agarose gel and purified using a DNA purification kit (Cytokine, Russia) and cloned into the pAL-TA vector (Evrogen, Russia). Inserts were detected by amplification with M13 primers and digested with endonucleases HhaI and HaeIII. Clone inserts with different restriction profiles were sequenced using ABI 3130xl Genetic Sequencer (Applied Biosystem, USA) (Table S1). Sequences were checked for chimeras with the Decipher tool [27].

The basic local alignment search tool (BLAST, http://blast .ncbi.nlm.nih.gov/) was used to compare sample sequences to closely related sequences from the NCBI database. Pairwise alignment was accomplished using BioEdit alignment editor version 7.0.9.0. [28] and phylogenetic reconstructions were performed in Mr. Bayes 3.2.1 and Mega 5 programs [29, 30].

For phylogenetic tree reconstruction maximum parsimony (MP), maximum likelihood (ML), and Bayesian analysis were performed. Kimura 2-parameter model was used for estimating of genetic distances [31]. The first two codon positions were used for analysis of $r b c \mathrm{~L}$ dataset (MP, ML). Bootstrap analysis was performed with 1000 replicates. In the Bayesian analysis, the MCMC chain was run for $1,000,000$, sampled every 100th step.
Sequences were deposited in the GenBank database under the following accession numbers: JX570937JX570966, KF856235-KF856242, and JX570967-JX571009 and KF856243-KF856253 for the 16S rRNA and rbcL genes, respectively.

\section{Results}

Clone library screening was performed to identify phototrophs associated with Baikalian sponges. The $16 \mathrm{~S}$ rRNA and $r b c \mathrm{~L}$ gene fragments were analysed in L. baicalensis, $L$. abietina, B. bacillifera and B. martinsoni. The chlorophyll level was estimated for three of these species and chlorophyll A was detected in L. baicalensis $(122 \pm 32 \mu \mathrm{g} / \mathrm{g})$, B. bacillifera $(37 \pm 12 \mu \mathrm{g} / \mathrm{g})$, and L. abietina $(20 \pm 0.5 \mu \mathrm{g} / \mathrm{g})$.

In total, 71 and 126 inserts were sequenced from the 16S rRNA and $r b c \mathrm{~L}$ clone libraries, respectively. Identical sequences were removed from further analysis and $38 \mathrm{16S}$ rRNA and $54 r b c \mathrm{~L}$ gene sequences were deposited in the GenBank database. Sequences obtained from 16S rRNA gene were $95-100 \%$ identical, while sequences obtained from the $r b c \mathrm{~L}$ gene were more heterogeneous (83-100\%). RbcL sequences with nucleotide identities greater than $90 \%$ were combined into operational taxonomic units (OTUs). There were three $\alpha$-cyanobacteria OTUs resolved from analysis of the $733 \mathrm{bp} r b c \mathrm{~L}$ gene alignment. The first OTU was $98 \%$ identical to Synechococcus rubescens (AM701775) while the maximum nucleotide sequence identities from two other OTUs were $87 \%$ and $89 \%$ similar to Cyanobium gracile 6307 (CP003495), and closer relatives could not be found in the GenBank database.

The phylogenetic analysis inferred from 16S rRNA and $r b c \mathrm{~L}$ genes showed three main clusters for Synechococcus which included sequences from all species of sponges and lake water analysed (Figures 1 and 2). Better resolved trees were based on $r b c \mathrm{~L}$ in comparison with $16 \mathrm{~S}$ rRNA based phylogeny. The phylogenetic reconstruction inferred from both genes showed that phylogenetic positions for two of three clusters were similar. There was a fully resolved cluster of S. rubescens that combined highly identical (99\%) sequences from Lake Baikal, as well as Synechococcus strains from European lakes. The two other groups were placed as sister clusters to S. rubescens (Figure 1). Clusters BL1 and BS1 included sequences from Lake Baikal only (Figures 1 and 2).

The phylogenetic positions of identified clusters were slightly different from the 16S rRNA based phylogeny. Using $16 \mathrm{~S}$ rRNA data, there was a cluster related to the S. rubescens phylogenetic lineage that included the clade of 23 Synechococcus sequences (intragroup identity 98-99\%) from Lake Baikal, sequences from lakes in Mongolia, and high altitude oligotrophic lakes of the Tibetan plateau and the Pyrenees, while $r b c L$-based phylogeny showed a specific cluster of 25 sequences that was sister to $S$. rubescens cluster (Figures 1 and 2). The rest of the sequences (16S rRNA tree) formed single branches or were clustered within Baikalian clades of picocyanobacteria from lake water (Figure 2).

The only $r b c \mathrm{~L}$ sequence from $B$. bacillifera (JX570973) that showed a low-level nucleotide identity $(<83 \%)$ with other 


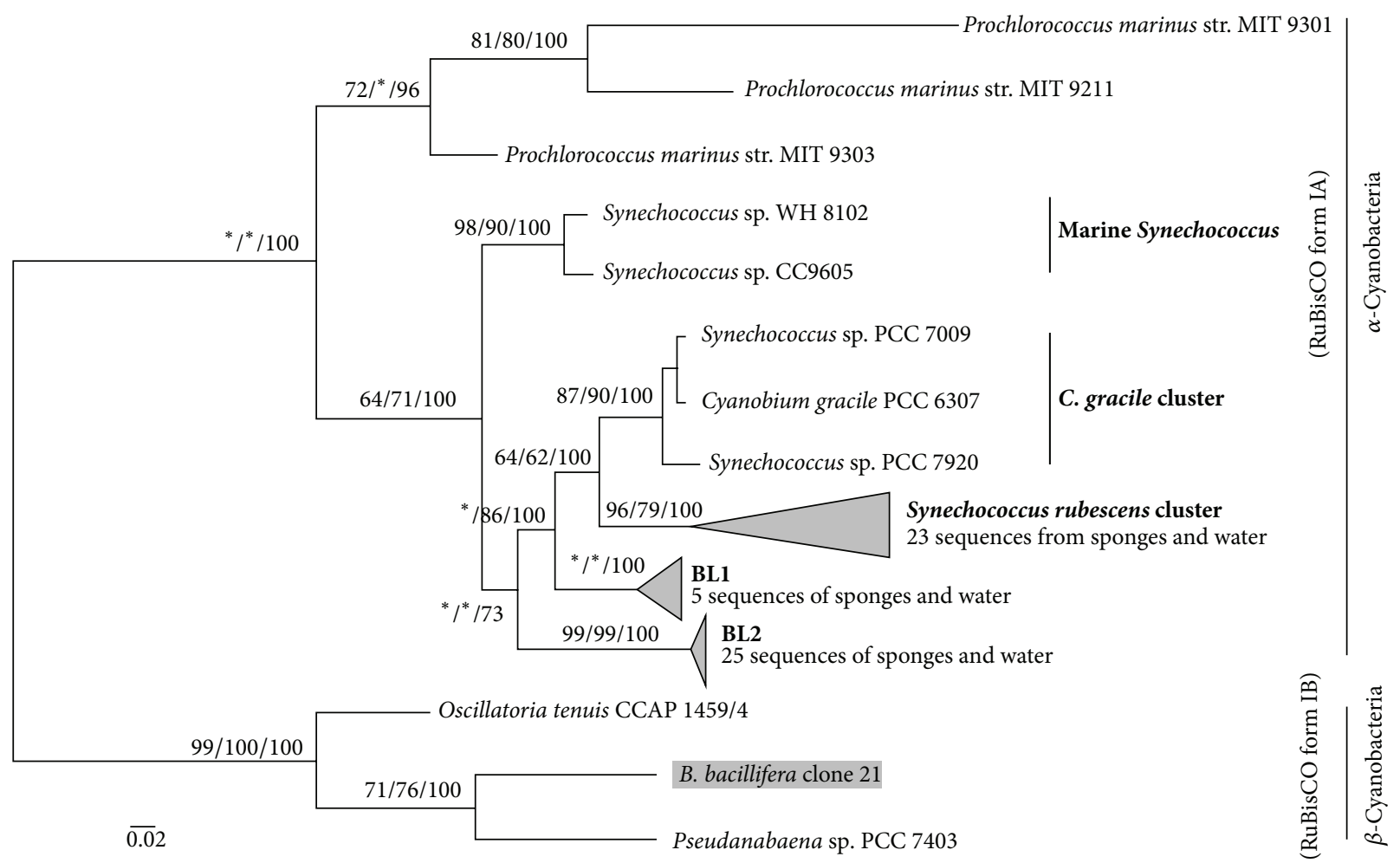

Figure 1: Phylogenetic tree of cyanobacteria associated with photosynthetic sponges from Lake Baikal. Consensus tree inferred from 733 nucleotide positions of the $r b c \mathrm{~L}$ gene. Clusters from Lubomirskiidae sponges are colored in grey. Bootstrap support values and posterior probability (\%) are shown at the nodes (Maximum Parsimony/Maximum Likelihood/Bayesian analysis). Values below 50\% are not shown. Scale bar represents 0.02 substitutions per site.

sequences from the GenBank database formed a distinct branch within the $\beta$-cyanobacteria (Figure 1).

Thus, the majority of sequences from sponges and water belonged to $\alpha$-cyanobacteria with form IA RuBisCO. Sequences from Baikalian sponges did not form distinct phylogenetic clusters and no major sponge-specific clusters have been found.

\section{Discussion}

The phylogeny inferred from 16S rRNA and $r b c \mathrm{~L}$ genes generally agrees that three main phylogenetic clusters for chlorophyll IA-containing picocyanobacteria are present in Baikalian sponges. The only one sequence belonging to Oscillatoria was detected in B. bacillifera. The finding of Synechococcus and Oscillatoria groups in freshwater sponges is similar to the results obtained from marine sponges [7, 8, 1719]. In contrast with marine sponges, no specific phylogenetic groups for sponge species or sponges with various levels of chlorophyll A were found, and sequences derived from sponges (as well as from lake water) were dispersed across the clusters described.

The different levels of chlorophyll $\mathrm{A}$ in sponges are also demonstrated in marine environments, where the major role for sponge-specific Synechococcus in ecology and primary productivity of sponges with high level of chlorophyll A has been described [7]. The highest level of chlorophyll A we found in L. baicalensis may be dependent on better light condition available to branched structures that grow up to one meter high in comparison to fully attached cushionand crust-like sponges (L. abietina, B. bacillifera, and B. martinsoni), though the presence of eukaryotic photosymbionts could also be significant.

The $S$. rubescens cluster detected in Baikalian sponges was affiliated with widely distributed Subalpine cluster I (group B) [20] proving high ecological plasticity of this group. The presence of phylogenetic clusters that included only Baikalian sequences, as well as clusters with no attribution to the Synechococcus phylogenetic group described, confirms the results of Pommier et al. [21] suggesting that endemic clusters are formed in the local bacterioplankton community in response to their adaptation to unique ecological conditions.

These results give a new insight into biodiversity of phototrophs associated with Baikalian sponges that could be further used for purpose of ecosystem monitoring. This is especially important with regard to increasing anthropogenic pressure as a result of tourism development in the Baikalian region.

\section{Conclusions}

Molecular detection of 16S rRNA and $r b c \mathrm{~L}$ genes from clone libraries were performed for the identification of phototrophs associated with four species of Lubomirskiidae from Lake 


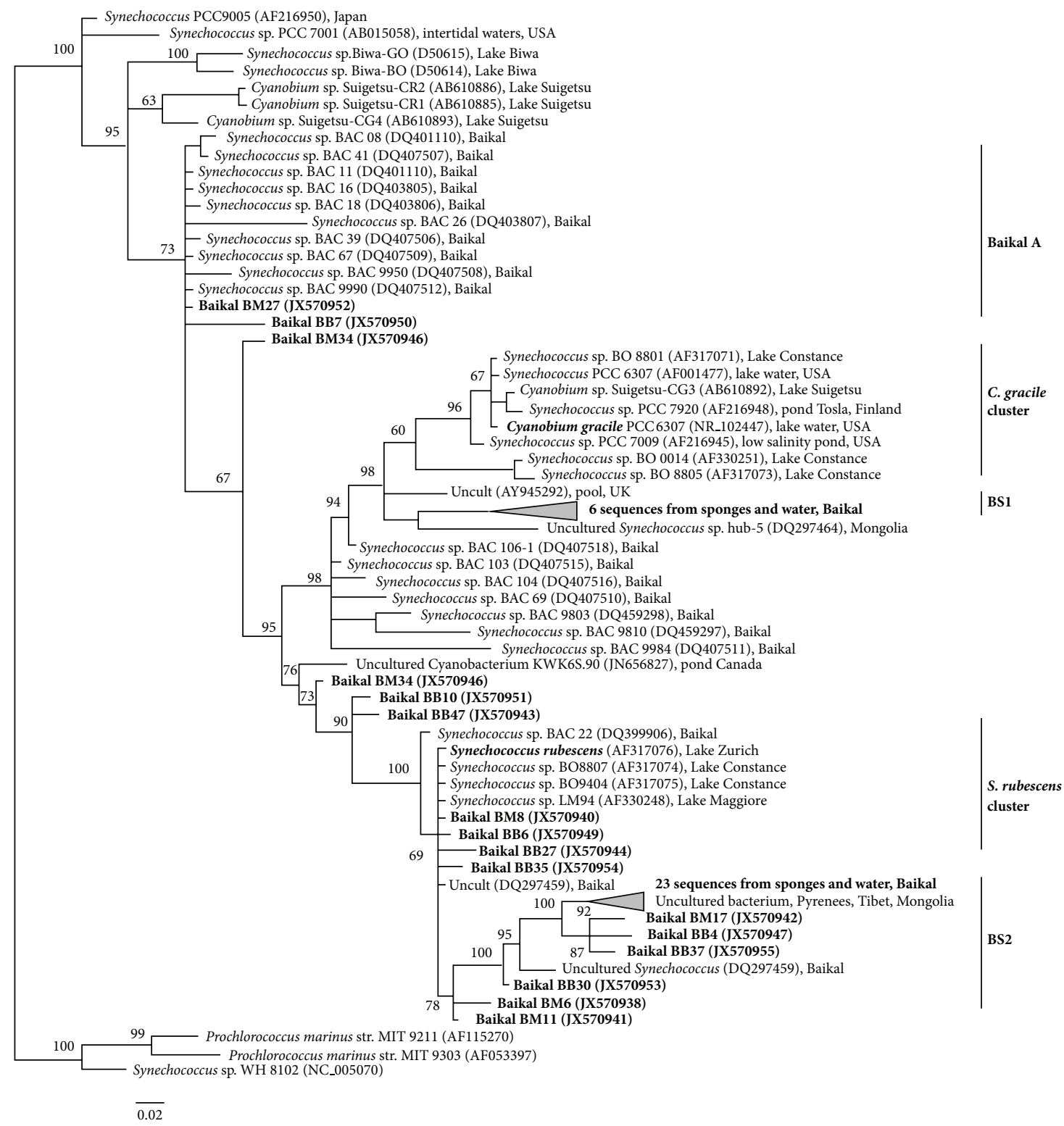

FIGURE 2: Phylogenetic tree of cyanobacteria associated with photosynthetic sponges from Lake Baikal inferred from 522 nucleotide positions of the 16S rRNA gene. Sequences from this study and reference sequences of S. rubescens and C. gracile are shown in bold. Bayesian posterior probability (\%) is shown at the nodes. Scale bar represents 0.2 substitutions per site. GenBank accession numbers are given in the parentheses. Accession numbers for 6 sequences from sponges and water, Baikal: JX570937, JX570945, JX570948, KF856235, KF856236, and KF856237; 23 sequences from sponges and water, Baikal: JX570939, JX570957-JX570966, KF856238-KF856242, and uncultured bacterium (Pyrenean, Tibetan, Mongolian lakes): HE857287, HE857263, HM129960, DQ297463, DQ422951, DQ297460, and DQ297461. In the Bayesian analysis, the MCMC chain was run for 2,000,000, sampled every 100th step.

Baikal. The phylogeny inferred from both genes showed that $S$. rubescens and two specific clusters of Synechococcus were associated with sponges and also found in lake water. Three major clusters of Synechococcus that did not form sponge-specific groups were detected in all studied species of Baikalian sponges. These results added to the understanding of symbiotic associations in freshwater photosynthetic sponges and could be further applied to the assessment of ecological impacts on the ecosystems in Lake Baikal.

\section{Conflict of Interests}

The authors declare that there is no conflict of interests regarding the publication of this paper.

\section{Authors' Contribution}

Nina V. Kulakova designed the study, identified the specimens, did molecular experiments, analysed sequences, and 
has written the paper. Natalia N. Denikina helped with the samples collections; Sergei I. Belikov helped with the study design.

\section{Acknowledgments}

The authors thank the diving team of the Limnological Institute, the SB RAS Genomics Core Facility, and Centre for Collective Use of LIN SB RAS for equipment and facilities. They are very grateful to Olga Maikova for help with morphological identification of sponges. This work was supported by Government Contract no. VI.50.1.4, "Molecular Ecology and Evolution of the Life Systems in Central Asia in the Models of Fishes, Sponges and Microorganisms Associated with Them."

\section{References}

[1] C. R. Wilkinson, "Microbial associations in sponges. I. Ecology, physiology and microbial populations of coral reef sponges," Marine Biology, vol. 49, no. 2, pp. 161-167, 1978.

[2] C. R. Wilkinson and J. Vacelet, "Transplantation of marine sponges to different conditions of light and current," Journal of Experimental Marine Biology and Ecology, vol. 37, no. 1, pp. 91$104,1979$.

[3] T. M. Frost and C. E. Williamson, "In situ determination of the effect of symbiotic algae on the growth of the freshwater sponge Spongilla lacustris," Journal of Ecology, vol. 61, pp. 1361-1370, 1980.

[4] A. A. Venn, J. E. Loram, and A. E. Douglas, "Photosynthetic symbioses in animals," Journal of Experimental Botany, vol. 59, no. 5, pp. 1069-1080, 2008.

[5] C. R. Wilkinson, "Net primary productivity in coral reef sponges," Science, vol. 219, no. 4583, pp. 410-412, 1983.

[6] K. M. Usher, "The ecology and phylogeny of cyanobacterial symbionts in sponges," Marine Ecology, vol. 29, no. 2, pp. 178192, 2008.

[7] P. M. Erwin and R. W. Thacker, "Incidence and identity of photosynthetic symbionts in Caribbean coral reef sponge assemblages," Journal of the Marine Biological Association of the United Kingdom, vol. 87, no. 6, pp. 1683-1692, 2007.

[8] M.-L. Lemloh, J. Fromont, F. Brümmer, and K. M. Usher, "Diversity and abundance of photosynthetic sponges in temperate Western Australia," BMC Ecology, vol. 9, article 4, 2009.

[9] S. M. Efremova, "New genus and new sponge species of the family Lubomirskiidae Rezvoy, 1936," in Index of Animal Species Inhabiting Lake Baikal and Its Catchment Area, vol. 1, book 2, pp. 1261-1278, Nauka, Novosibirsk, Russia, 2004.

[10] C. R. Wilkinson, "Nutrient translocation from green algal symbionts to the freshwater sponge Ephydatia fluviatilis," Hydrobiologia, vol. 75, no. 3, pp. 241-250, 1980.

[11] T. M. Frost, L. E. Graham, J. E. Elias, M. J. Haase, D. W. Kretchmer, and J. A. Kranzfelder, "A yellow-green algal symbiont in the freshwater sponge, Corvomeyenia everetti: convergent evolution of symbiotic associations," Freshwater Biology, vol. 38, no. 2, pp. 395-399, 1997.

[12] C. Gernert, F. O. Glöckner, G. Krohne, and U. Hentschel, "Microbial diversity of the freshwater sponge Spongilla lacustris," Microbial Ecology, vol. 50, no. 2, pp. 206-212, 2005.
[13] S. Handa, M. Nakahara, H. Tsubota, H. Deguchi, Y. Masuda, and T. Nakano, "Choricystis minor (Trebouxiophyceae, Chlorophyta) as a symbiont of several species of freshwater sponge," Hikobia, vol. 14, no. 4, pp. 365-373, 2006.

[14] O. V. Kaliuzhnaia, A. A. Krivich, and V. B. Itskovich, "Diversity of $16 \mathrm{~S}$ rRNA genes in metagenomic community of the freshwater sponge Lubomirskia baicalensis," Genetika, vol. 48, no. 8, pp. 1003-1006, 2012 (Russian).

[15] H. E. Elsaied, H. Kimura, and T. Naganuma, "Composition of archaeal, bacterial, and eukaryal RuBisCO genotypes in three Western Pacific arc hydrothermal vent systems," Extremophiles, vol. 11, no. 1, pp. 191-202, 2007.

[16] H. Elsaied and T. Naganuma, "Phylogenetic diversity of ribulose-1,5-bisphosphate carboxylase/oxygenase large-subunit genes from deep-sea microorganisms," Applied and Environmental Microbiology, vol. 67, no. 4, pp. 1751-1765, 2001.

[17] L. Steindler, D. Huchon, A. Avni, and M. Ilan, "16S rRNA phylogeny of sponge-associated cyanobacteria," Applied and Environmental Microbiology, vol. 71, no. 7, pp. 4127-4131, 2005.

[18] U. Hentschel, J. Hopke, M. Horn et al., "Molecular evidence for a uniform microbial community in sponges from different oceans," Applied and Environmental Microbiology, vol. 68, no. 9, pp. 4431-4440, 2002.

[19] R. L. Simister, P. Deines, E. S. Botté, N. S. Webster, and M. W. Taylor, "Sponge-specific clusters revisited: a comprehensive phylogeny of sponge-associated microorganisms," Environmental Microbiology, vol. 14, no. 2, pp. 517-524, 2012.

[20] N. D. Crosbie, M. Pöckl, and T. Weisse, "Dispersal and phylogenetic diversity of nonmarine picocyanobacteria, inferred from 16S rRNA gene and cpcBA-intergenic spacer sequence analyses," Applied and Environmental Microbiology, vol. 69, no. 9, pp. 5716-5721, 2003.

[21] T. Pommier, B. Canbäck, L. Riemann et al., "Global patterns of diversity and community structure in marine bacterioplankton," Molecular Ecology, vol. 16, no. 4, pp. 867-880, 2007.

[22] P. D. Rezvoi, "Freshwater sponges of the USSR," in The Fauna of the USSR, D. P. Rezvoi, Ed., vol. 2, pp. 21-41, Academy of Sciences, Moscow, Russia, 1936.

[23] S. M. Efremova, "Porifera," in An Annotated List of the Fauna of Lake Baikal and Its Catchment Area, O. A. Timoshkin, Ed., vol. 1, pp. 177-190, Nauka, Novosibirsk, Russia, 2001, (Russian).

[24] M. Bergmann and R. H. Peters, "A simple reflectance method for the measurement of particulate pigment in lake water and its application to Phosphorus-Chlorophyll-Seston Relationships," Canadian Journal of Fisheries and Aquatic Sciences, vol. 37, pp. 111-114, 1980.

[25] D. J. Webb, B. K. Burnison, A. M. Trimbee, and E. E. Prepas, "Comparison of chlorophyll a extractions with ethanol and dimethyl sulfoxide/acetone, and a concern about spectrophotometric phaeopigment correction," Canadian Journal of Fisheries and Aquatic Sciences, vol. 49, pp. 2331-2336, 1992.

[26] U. Nübel, F. Garcia-Pichel, and G. Muyzer, "PCR primers to amplify 16S rRNA genes from cyanobacteria," Applied and Environmental Microbiology, vol. 63, no. 8, pp. 3327-3332, 1997.

[27] E. S. Wright, L. S. Yilmaz, and D. R. Noguera, "DECIPHER, a search-based approach to chimera identification for 16S rRNA sequences," Applied and Environmental Microbiology, vol. 78, no. 3, pp. 717-725, 2012.

[28] T. A. Hall, "BioEdit: a user-friendly biological sequence alignment editor and analysis program for Windows 95/98/NT," Nucleic Acids Symposium Series, vol. 41, pp. 95-98, 1999. 
[29] F. Ronquist, M. Teslenko, P. van der Mark et al., "Mrbayes 3.2: efficient bayesian phylogenetic inference and model choice across a large model space," Systematic Biology, vol. 61, no. 3, pp. 539-542, 2012.

[30] K. Tamura, D. Peterson, N. Peterson, G. Stecher, M. Nei, and S. Kumar, "MEGA5: molecular evolutionary genetics analysis using maximum likelihood, evolutionary distance, and maximum parsimony methods," Molecular Biology and Evolution, vol. 28, no. 10, pp. 2731-2739, 2011.

[31] M. Kimura, "A simple method for estimating evolutionary rates of base substitutions through comparative studies of nucleotide sequences," Journal of Molecular Evolution, vol. 16, no. 2, pp. 111120, 1980. 

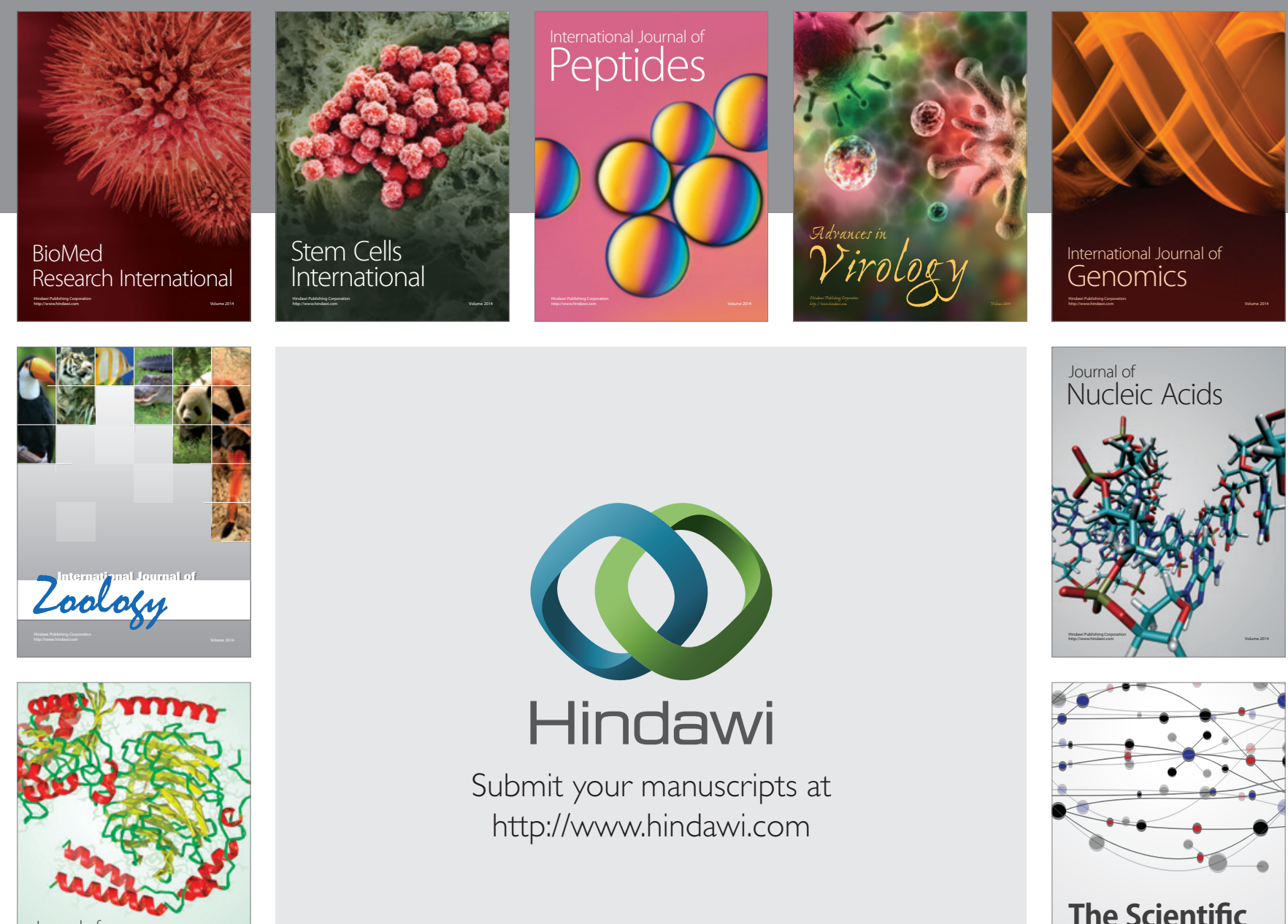

Submit your manuscripts at

http://www.hindawi.com

Journal of
Signal Transduction
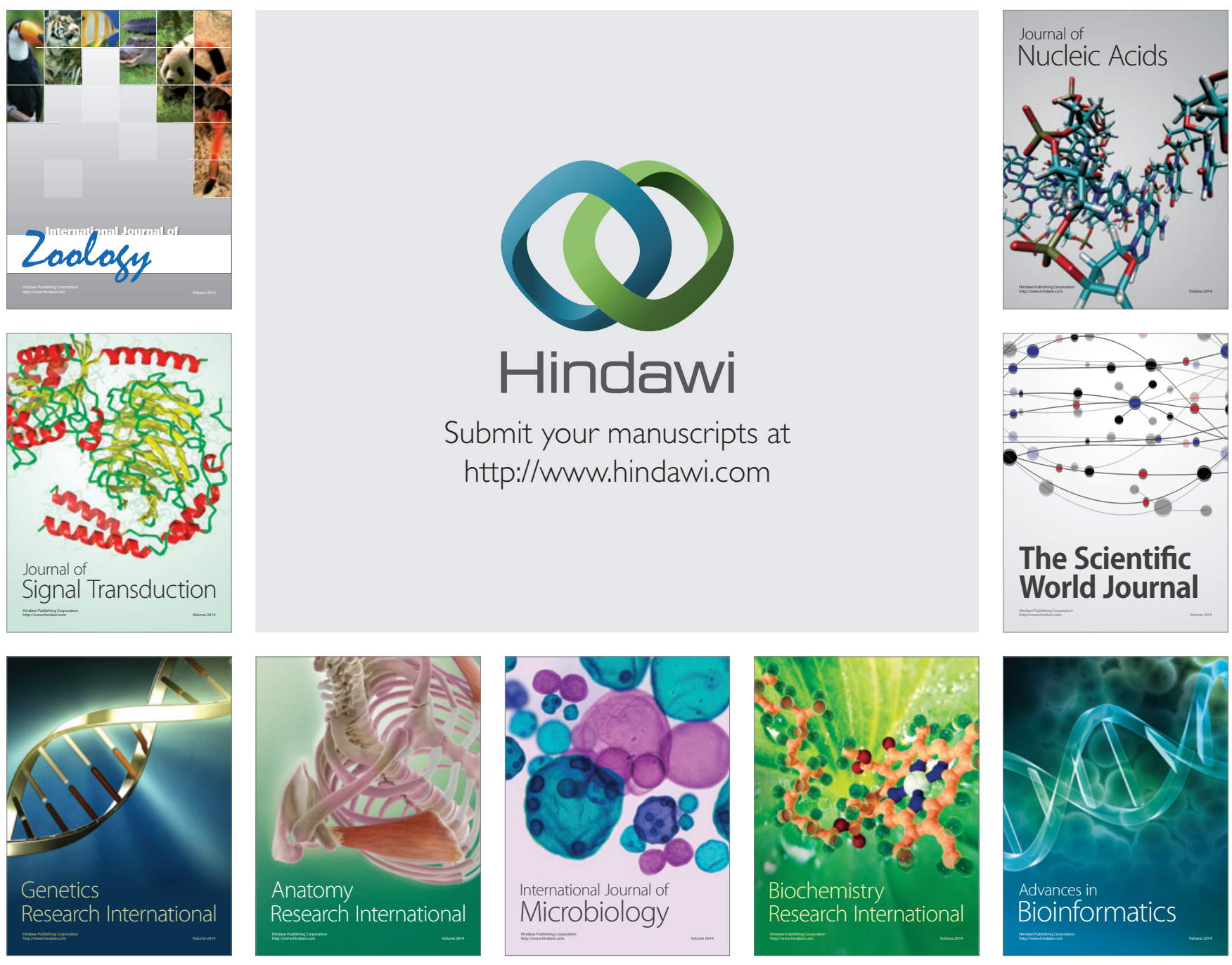

The Scientific World Journal
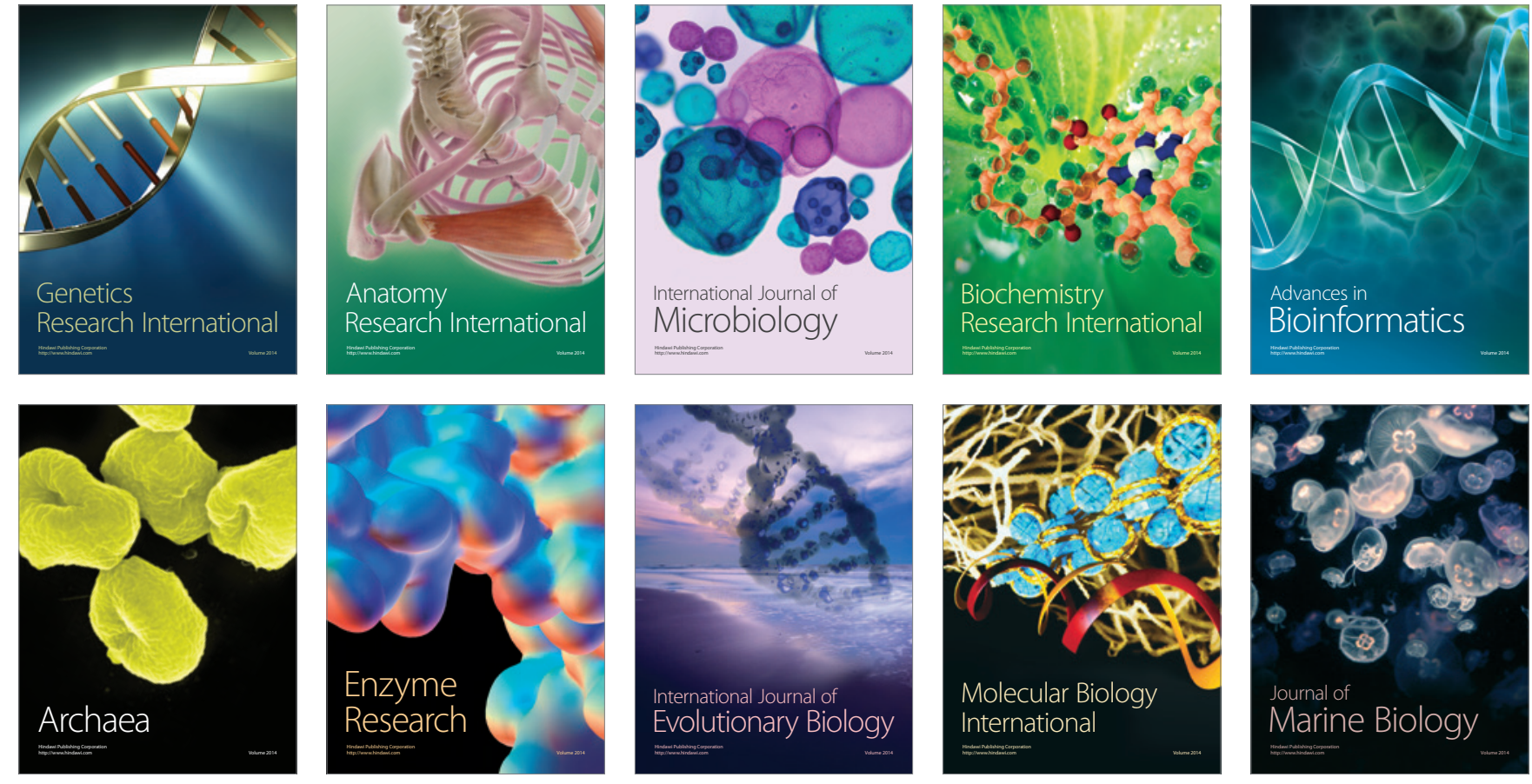